\title{
COR TRILOCULARE BIATRIATUM
}

\author{
BY \\ H. G. PENMAN AND R. HEDWORTH WHITTY \\ From Queen Alexandra Hospital, Cosham, Hants.
}

Cor triloculare biatriatum is a rare anomaly. Campbell, Reynolds, and Trounce (1953) could find descriptions of only 85 cases of hearts with single ventricle, including seven of their own, and at least 27 of these patients had cor biloculare, while one (Herndon's case) appears in fact to have had Fallot's tetralogy. We have found descriptions of eight further cases of cor triloculare biatriatum published since that time (van Buchem, Nieveen, and Marring, 1954; Harley (two cases), 1958; Barry and Isaac, 1953; Rawson and Doerner, 1953; Drew, Fleming, and Johnson, 1955; Heath, 1957; Lumish, Deshmukh, and Likoff, 1959). The first two papers quoted refer to living patients. The only patients with this condition reported to have reached the age of 30 or more were four included in Campbell et al.'s series (excluding Herndon's case) and those described by van Buchem et al. and by Rawson and Doerner-six in all.

For these reasons we record the following case, in which the patient died aged 30 years, having survived three pregnancies to 36 weeks or beyond.

\section{Case Report}

The patient's period of close supervision started when, aged 23, she attended Mr. Trevor Barnett's ante-natal clinic on August 9, 1954, being then almost four months pregnant. Because of an obvious cardiac abnormality she was referred to Dr. Ralph Moore for a medical opinion. She said that because of a "weak heart" she had, as a child, attended the school clinic and had not been allowed to do physical training. During childhood she had also had recurrent bronchitis. She had always been slightly dyspnœic on effort, and sometimes experienced a little substernal pain, for instance when cycling. A few months before becoming pregnant, however, she had evidently been passed on Mass Miniature Radiography. There had been no previous pregnancies.

Her heart was grossly enlarged, with a systolic murmur and thrill maximal in the 2nd and 3rd spaces to the left of the sternum, and a diastolic murmur in the pulmonary area and down the left sternal edge. The second sound in the pulmonary area was loud and split. Blood pressure was $110 / 70 \mathrm{~mm}$. $\mathrm{Hg}$, there were no signs of cardiac failure, and she was not cyanosed. Screening showed a large overactive heart, with some degree of hilar dance. The left atrium was large and showed systolic pulsation. Both ventricles and the pulmonary artery were large, but the aorta was small. The electrocardiogram showed sinus tachycardia with slight right axis deviation. The $P$ wave in standard lead I was bifid. QRS measured $0.12 \mathrm{sec}$. in the chest leads.

The pregnancy progressed uneventfully, but the patient forestalled plans for a three weeks' rest in hospital before delivery by starting labour at 36 weeks. This, apart from some cyanosis in the second stage, was uneventful, the total duration being $7 \frac{3}{4}$ hours. A male infant weighing $5 \mathrm{lb} .4 \mathrm{oz}$. $(2.38 \mathrm{~kg}$.) was born, but unhappily the baby died the following day, autopsy revealing atelectasis due to extensive hyaline membrane formation. The heart was structurally normal.

Recovery was satisfactory, and she returned home to her housework. She failed to reattend the clinic until January 1956 when she proclaimed herself pregnant again. After some discussion, cardiac catheterization was postponed till after the pregnancy, the possibility of radiation hazard being the final deciding factor. 
No graver symtoms developed than some tiredness and slight ankle œdema. She was delivered at 38 weeks, again without previous hospital rest, of a normal $7 \mathrm{lb} .4 \mathrm{oz}$. $\left(3.29 \mathrm{~kg}\right.$.) male infant after a $1 \frac{1}{2}$-hour labour. Recovery again was rapid.

She was not seen again until 1960 when she became pregnant once more, but this time, at about 25 weeks, noticed more breathlessness. She was admitted to hospital a fortnight later for a month's rest. Slight cyanosis was noted, but otherwise the signs were substantially as before. In the last month of the pregnancy, however, the dyspnœa increased, and ankle œdema and obvious cyanosis at rest appeared. Chlorothiazide was given, and she improved. At 39 weeks, on

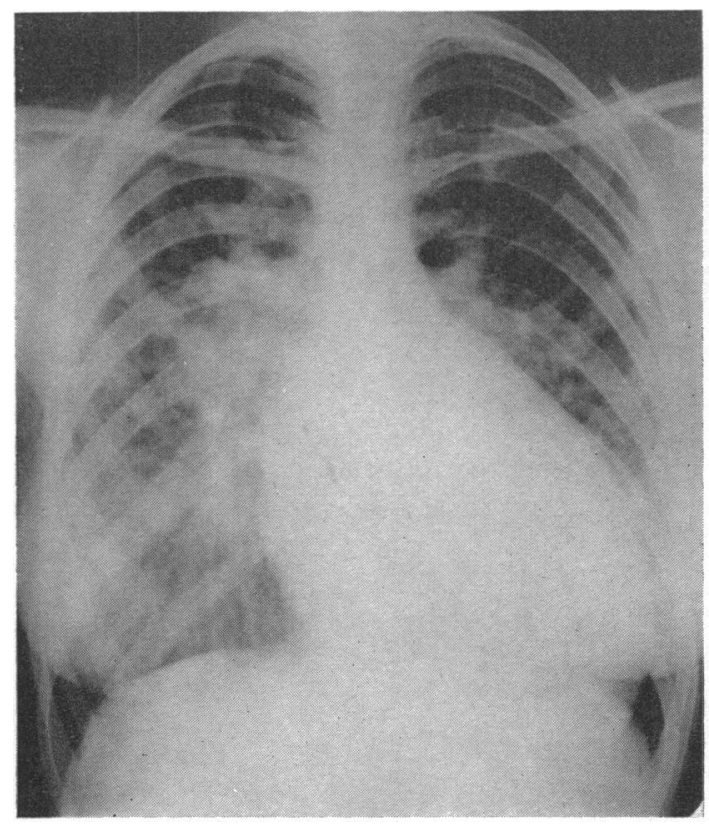

FIG. 1.-Radiograph in 1955, showing hypertrophy.
November 25, 1960, after two hours and 10 minutes labour, a 7 lb. $10 \mathrm{oz}$. (3.46 kg.) male infant was born. Eight days later, her hands and feet were cyanosed, and the jugular venous pressure was raised 5 inches with a big $Y$ descent. A fourth sound was heard at the apex, and the loud second sound in the pul monary area just split in expiration. There was a pansystolic murmur, with a thrill, maximal at the left sternal edge in the second and third spaces; a diminuendo diastolic murmur, which was not pandiastolic, was heard in the same area. Treatment with diuretics was continued and she was able to return home before Christmas.

On February 15, 1961 she was readmitted under the care of Dr. Moore in right-sided cardiac failure, and was found for the first time to have atrial fibrillation, with an apical rate of 170 a minute. It proved impossible to control the fibrillation adequately. The cardiac failure became worse and the patient died a month later, aged 30, a final effort at resuscitation, by means of direct cardiac massage, having failed.

Necropsy. This was a well-nourished woman with œdema of legs and ankles, and a cardiac massage incision.

The heart was enormous, weighing $825 \mathrm{~g}$. Moderately dilated but otherwise normal atria led through tricuspid and mitral valves into a single huge ventricular cavity whose wall was of normal adult left ventricular thickness throughout. From the uppermost part of this ventricle sprang the aorta, immediately in front of the pulmonary artery. The mitral valve was placed behind the pulmonary orifice (Fig. 2). In the upper part of the anterior and right wall of the ventricle, about $2 \mathrm{~cm}$. below the aortic valve, was a pocketlike opening, that led down into an extensive cleft in the wall of the ventricle (Fig. 3). There was, therefore, a rudimentary chamber but this showed no opening except that into the main ventricular cavity. The inner margin of the opening of the "pocket" formed part of the boundary of a somewhat narrowed subaortic channel (Fig. 3). The leaflets of all the valves were normal in number, but were irregularly thickened, with calcification in the mitral. The pulmonary valve might well have been incompetent. The pulmonary orifice, after fixation, measured $8 \mathrm{~cm}$. in circumference, and the aortic $7 \mathrm{~cm}$. The pulmonary trunk was greatly dilated, and the aorta hypoplastic throughout as were the otherwise normal large arteries arising from its arch. The aortic sinuses were placed one anteriorly and two posterolaterally. From each posterolateral sinus a coronary artery originated. These coursed round to the back of the heart in the atrio-ventricular grooves, the small terminal portion of the right coronary running down in the posterior interventricular groove. The left coronary gave off, $0.5 \mathrm{~cm}$. from its origin, an anterior descending branch. The coronary sinus was normal. There was neither localized coarctation nor patent ductus, and the pulmonary veins were normal. In the abdomen, the only abnormal findings were in the liver and spleen which showed evidence of chronic passive venous congestion. The brain appeared normal. A notable histological feature in the sections from the lungs was the large number of arterioles and small arteries per field, these arteries being strikingly dilated and thin-walled. Heath (1957) also noted this feature, and gave a full account of his study of the pulmonary vasculature in this condition. There was no evidence of pulmonary œdema. 


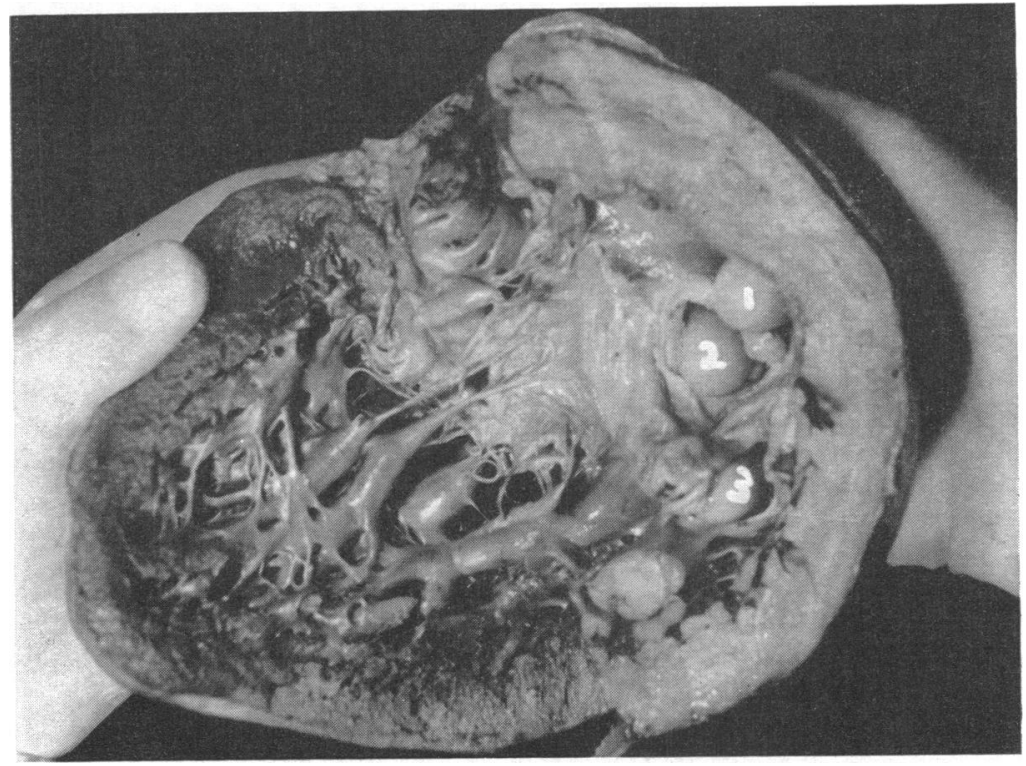

Fig. 2.-The opened ventricle viewed from below (anterior surface above and to the right). Numbered figures are in the valve orifices: aortic (1), pulmonary (2), and mitral (3). The tricuspid valve ring has been opened, and the leaflets appear to the left of the three figures.

FIG. 3.-Valves from below (hand holding the front of the heart). The forceps is placed through the aortic orifice and into the top of the "pocket" in the ventricular wall. The lower portion of this part of the wall has been reflected and is shown in the upper part of the figure.

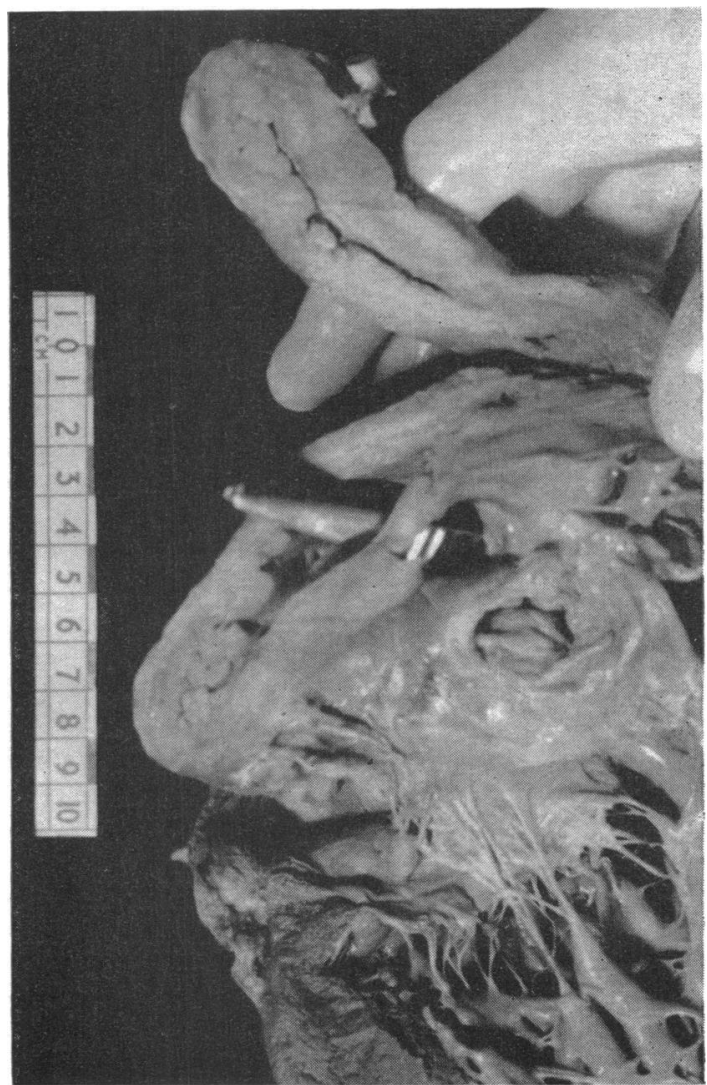




\section{Discussion}

The case is remarkable in the age attained by the patient, but particularly in her three pregnancies. In other respects, the usual features of this congenital anomaly are shown. The heart belongs to Rogers and Edwards' (1951) Type 1A, having a narrow subaortic channel. This is the least rare of the varieties they describe. There were no gross associated congenital defects. Those most frequently noted previously are patent ductus, coarctation of the aorta, atrial septal defect, bicuspid aortic and pulmonary valves, two instead of four pulmonary veins, dextrocardia with or without transposition of the viscera, and mongolism.

The minor degree of cyanosis, at first sight surprising, is a usual finding in those surviving early childhood. Another perhaps unexpected feature is the absence of gross abnormalities in the cardiogram. This again is the usual finding, as intracardiac conduction time is usually normal, and bundle-branch block is rarely found (Heath 1957). Campbell et al. (1953), and Richman (1950) discuss this curious feature.

Our patient followed the well-recognized tendency for those with heart disease to have quick labours, and Morgan Jones (1959) emphasized that in most forms of congenital heart disease pregnancy is remarkably safe. However, as already noted, we have been unable to find a previous record of pregnancy, successful or otherwise, in a patient with cor triloculare biatriatum.

\section{Summary}

A case of cor triloculare biatriatum is described. In reaching the age of 30 the patient was exceptional: in surviving three pregnancies to term she was possibly unique.

Published material on the condition is briefly reviewed, and certain of the more important features of the anomaly are discussed.

We are grateful to Dr. Ralph Moore for advice in the preparation of this report; we thank him and Mr. Trevor Barnett, under whose combined care the patient did well for so long, for kindly allowing us to publish details of the case. We also thank Dr. R. D. Clay for his post-mortem report on the infant.

\section{References}

Barry, D. R., and Isaac, D. H. (1953). Brit. med. J., 2, 921.

Buchem, F. S. P. van, Nieveen, J., and Marring, W. (1954). Cardiologia (Basel), 24, 135.

Campbell, M., Reynolds, G., and Trounce, J. R. (1953). Guv's Hosp. Rep., 102, 99.

Drew, C. E., Fleming, P. R., and Johnson, A. M. (1955). Brit. Heart J., 17, 414.

Harley, H. R. S. (1958). Guy's Hosp. Rep., 107, 116.

Heath, D. (1957). Circulation, 15, 701.

Jones, M. (1959). Proc. roy. Soc. Med., 52, 767.

Lumish, S. H., Deshmukh, M. H., and Likoff, (1959). Amer. J. Cardiol., 4, 535.

Rawson, F. L., and Doerner, A. A. (1953). Amer. Heart J., 46, 779.

Richman, B. (1950). Amer. Heart J., 39, 887.

Rogers, H. M., and Edwards, J. E. (1951). Amer. Heart J., 41, 299. 